\title{
A RETROSPECTIVE ANALYSIS OF PATIENTS WITH ADVANCED RENAL CELL CARCINOMA TREATED WITH TEMSIROLIMUS
}

\author{
Christina Ng \\ Cancer Institute, Pantai Hospital, Kuala Lumpur, Malaysia.
}

\begin{abstract}
:
The clinical experience of the novel drug temsirolimus on eight patients with metastatic renal cell carcinoma and who were refractory to other forms of treatment is reported. Although none of the patients showed complete or partial response, three patients had stable disease. One patient was prematurely withdrawn due to pneumonitis. Five patients died during the period of observation of twenty months and the median survival time from start of treatment was ten months. Three patients showed no evidence of adverse events (AE). Five patients showed dyslipidemia and two had pneumonitis for which, the drug had to be withdrawn in one of them. None had significant leucopenia. We conclude that temsirolimus has activity even in heavily pretreated patients in advanced renal cell carcinoma and in addition, has the benefits of ease of administration and good tolerability. (JUMMEC 2010; 13 (1): 19-23)
\end{abstract}

KEYWORDS: temsirolimus, metastatic renal cell carcinoma, adverse events

\section{Introduction}

Renal cell carcinoma (RCC) represents $2-3 \%$ of all cancers and there appears to be a gradual increase in its incidence (1). It is often diagnosed late and distant metastases are present in more than one-third of cases. It is usually asymptomatic and the classic triad of flank pain, gross haematuria and palpable abdominal mass is now a rarity (2). A very important prognostic indicator is its stage (3). Of the histological types the clear cell type is the commonest, occurring in about 80 to $90 \%$ of cases (4).

Nephrectomy is the primary treatment of choice. But in the presence of metastatic disease conventional chemotherapy, radiotherapy or even immunotherapy are ineffective. Molecular targeted therapy is recommended (5). The first line therapy for patients with good to intermediate prognosis has been sunitinib or sorafenib. Interleukin-2 and interferon alpha alone or in combination have also been used. In patients with poor prognosis temsirolimus is recommended (6). Its effective use in advanced renal cell carcinoma has been observed in Phase 2 trials and improved survival reported in phase 3 trials $(7,8)$.

The main objective of the study was to assess our experience of temsirolimus in patients with advanced renal cell carcinoma who were treated in a local setting as per standard of care. In particular the objectives were three.

Firstly, it was to assess the efficacy of temsirolimus in terms of the number of patients deriving clinical benefit in a group of patients with advanced disease and who were not responsive to other treatment modalities. Secondly, to assess the incidence, type and degree of adverse events seen and thirdly, to assess the survival rate following treatment with temsirolimus in this small group of patients

\section{Methods}

The case records of eight patients with advanced renal cell carcinoma and who were treated with temsirolimus were reviewed. All patients had nephrectomies and some form of prior treatment. Such treatment included either radiotherapy, alpha-inteferon, sunitinib, sorafenib or pazopanib.
Correspondence:
Christina $\mathrm{Ng}$
Cancer Institute
Pantai Hospital KL
59100 Kuala Lumpur, Malaysia
Email:ngchristina.dr@gmail.com 
Patients were administered intravenous temsirolimus $25 \mathrm{mg}$ as an intravenous infusion over no less than 30 minutes but with completion of infusion within 60 minutes. Premedication with intravenous diphenhhydramine 25 to $50 \mathrm{mg}$ was given about 30 minutes prior to treatment. The treatment was repeated weekly up and until either the drug had to be stopped due to toxicity or if there was disease progression.

Clinical benefit was defined as the patient having complete response, partial response or if they remained in stable disease. No benefit was when the patient went on to progressive disease after a minimum of eight doses of temsirolimus or when the drug had to withdrawn due to toxicity. Response to treatment was assessed based on clinical grounds and where indicated, radiologically either by x-rays or CT scans.

The adverse events were recorded and graded according to the National Cancer Institute Common Terminology Criteria for Adverse Events ( $\mathrm{NCI}$ CTC AE v3.0) (9). Survival was based on all-cause mortality.

\section{Results}

There were eight patients with advanced and metastatic renal cell carcinoma who were treated with temsirolimus. Their clinical characteristics are summarized in Table 1. All had lung metastases at the time of commencement of treatment. Most had prior treatment with either interferon, sunitinib, sorafenib or pazopanib.

Table 1: The demographic and clinical characteristics of the patients in the study

\begin{tabular}{|c|c|c|c|c|c|c|}
\hline Patient & Age (years) & Gender & Histology & $\begin{array}{l}\text { Stage at } \\
\text { diagnosis }\end{array}$ & Prior treatment & $\begin{array}{c}\text { Site of metastasis at start of } \\
\text { temsirolimus }\end{array}$ \\
\hline 1 & 57 & Male & Clear cell & 1 & Interferon & $\begin{array}{l}\text { Lungs, } \\
\text { bone adrenal }\end{array}$ \\
\hline 2 & 31 & Male & Clear cell & 3 & Sunitinib & $\begin{array}{c}\text { Lung, } \\
\text { bone, } \\
\text { lymph node, } \\
\text { adrenal }\end{array}$ \\
\hline 3 & 44 & Male & Clear cell & 2 & $\begin{array}{c}\text { Sunitinib, } \\
\text { Sorafenib } \\
\text { Pazopanib }\end{array}$ & $\begin{array}{l}\text { Lung, } \\
\text { lymph nodes }\end{array}$ \\
\hline 4 & 55 & Male & Clear cell & 3 & $\begin{array}{l}\text { Sunitinib, } \\
\text { Sorafenib }\end{array}$ & Lung \\
\hline 5 & 51 & Male & Clear cell & 3 & $\begin{array}{l}\text { Radiotherapy } \\
\text { Sunitinib }\end{array}$ & $\begin{array}{l}\text { Lung, } \\
\text { bone, } \\
\text { adrenal }\end{array}$ \\
\hline 6 & 50 & Female & Clear cell & 4 & $\begin{array}{l}\text { Chemotherapy } \\
\text { Sunitinib }\end{array}$ & Lung \\
\hline 7 & 46 & Male & Clear cell & 2 & $\begin{array}{c}\text { Interferon } \\
\text { Pazopanib }\end{array}$ & Lung \\
\hline 8 & 47 & Female & Clear cell & 4 & $\begin{array}{c}\text { Interferon } \\
\text { Interleukin } \\
\text { Sunitinib } \\
\text { Dendritic cell vaccine } \\
\text { Bevacizumab } \\
\text { Sirolimus }\end{array}$ & Lung \\
\hline
\end{tabular}


There were seven patients who had completed a minimum of eight doses. One patient had died after three doses were given i.e. patient number 4 . In terms of response, none of the patients showed complete or partial response. However, three patients had stable disease while on treatment i.e. patient number 5, 6, and 8 . The remaining four patients showed either progressive disease or died soon after eight does of the drug were given.

Of the eight patients, three showed no evidence of adverse events ( $A E)$. In the remaining five patients the number of patients affected, type, grade and outcome of the adverse events seen is summarized in Table 2 . Of interest was the relatively frequent incidence of some form of dyslipidemia. All these patients were non-dyslipidemic before treatment. Also seen were two cases of pneumonitis ; in one, the drug had to be withdrawn temporarily and in the other after 20 doses were given. The implications of these findings are discussed.

Five patients died during the period of observation and their survival pattern in this group of patients is shown in Figure 1. The median survival time from start of treatment was ten months.

\section{Discussion}

Metastatic renal cell carcinoma is a therapeutic challenge because of its poor response to conventional chemotherapy and radiotherapy. Over the last few years, three agents that target critical signaling components involved in tumor angiogenesis and tumor cell proliferation-sorafenib, sunitinib and temsirolimus have been approved for use in metastatic renal cell carcinoma. While the first two agents have been recommended as first or second line treatment for all patients, temsirolimus has been recommended as first line only for patients with poor prognosis $(5,6)$.

The results of the present study show that although none of the eight patients showed complete or partial response to temsirolimus, three patients had stable disease. It must be remembered that these patients were patients with metastatic disease and who did not respond to other treatment. Notwithstanding,

Table 2: Adverse events seen in the patients

\begin{tabular}{|c|c|c|c|c|c|}
\hline $\begin{array}{c}\text { Number of } \\
\text { patients }\end{array}$ & Adverse event (AE) & Grade* & Treatment & $\begin{array}{c}\text { Action to study } \\
\text { drug }\end{array}$ & Outcome \\
\hline 2 & Leucopenia & 1 & None & Continued & Resolved \\
\hline 2 & Pneumonitis & $1 \& 3$ & Symptomatic & Stopped & Resolved \\
\hline 3 & Mouth ulcer & 1 & Symptomatic & Continued & Resolved \\
\hline 3 & Rash over arm face and neck & 1 & Symptomatic & Continued & Resolved \\
\hline 4 & Hypercholesterolemia & $1 \& 2$ & Fenofibrate & Continued & Resolved \\
\hline 1 & Deranged liver function tests & 3 & None & Stopped temporarily & Resolved \\
\hline 2 & Hyperlipdemia & $1 \& 2$ & Fenofibrate & Continued & Resolved \\
\hline 1 & Dry mouth/stomatitis & 1 & Symptomatic & Continued & Resolved \\
\hline 1 & Chest discomfort & 1 & Symptomatic & Continued & Resolved \\
\hline 1 & Photosensitivity & 2 & Avoid light/creams & Continued & Resolved \\
\hline 1 & Facial edema & 2 & None & Continued & Resolved \\
\hline 1 & Dry tongue/stomatitis & 1 & Symptomatic & Continued & Resolved \\
\hline 1 & Alteration to taste & 1 & None & Continued & Unresolved \\
\hline 1 & Epistaxis & 1 & Symptomatic & Continued & Resolved \\
\hline 1 & $\begin{array}{l}\text { Hyperpigmentation over } \\
\text { arms and buttocks }\end{array}$ & 1 & None & Continued & Resolved \\
\hline
\end{tabular}

* $1=$ mild $A E ; 2$ =moderate $A E ; 3=$ severe $A E ; 4=$ life threatening or disabling $A E ; 5=$ death related to $A E$ 


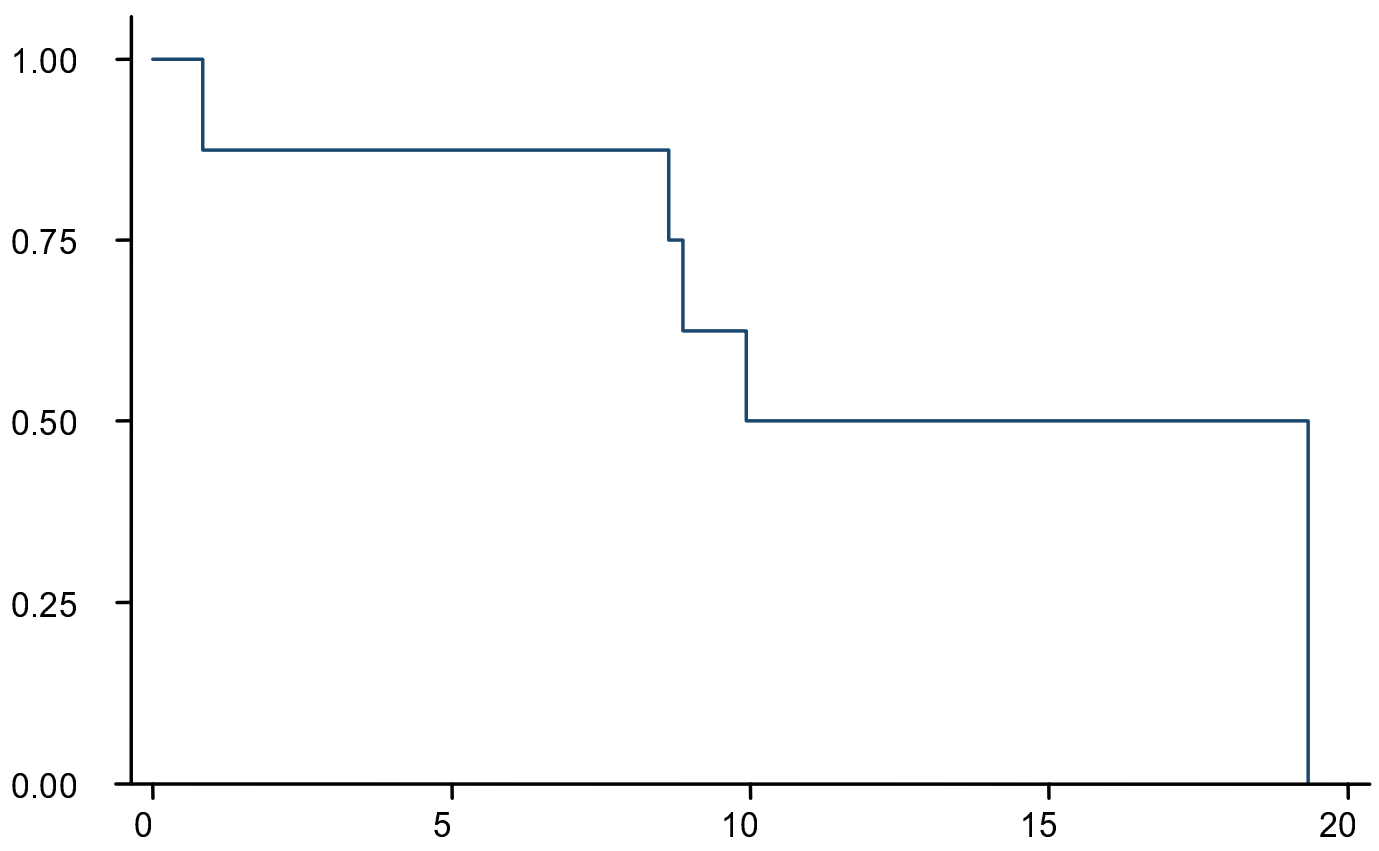

Survival time in months from start of treatment

Figure 1: Kaplan-Meier Survival pattern of eight patients

the overall median survival rate was 10 months from commencement of treatment.

In a multicentre trial involving 626 patients with previously untreated poor-prognosis metastatic renal cell carcinoma receiving either alpha-inteferon alone, temsirolimus or a combination of the two showed that when compared to alpha interferon, temsirolimus improved the survival rate. The addition of interferon did not make any difference to the survival rate (8). Of interest was that the survival in the temsirolimus only treated group was similar to ours being close to 10.8 months.

The pharmacological action of temsirolimus is novel. It is an antineoplastic agent that acts as a selective inhibitor for mTOR(mammalian target of rapamycin) kinase (10), a signaling pathway involved in the growth and proliferation of cells. Temsilorimus, a rapamycin analogue, acts as a selective inhibitor of mTOR by binding to an intracellular protein (FKBP-12) and the protein-drug complex binds and inhibits the activity of mTOR that in turn controls cell division (11). High concentrations result in complete cell growth inhibition in vitro, whereas inhibition mediated by FKBP12/ temsirolimus complex alone results in approximately $50 \%$ decrease in cell proliferation. Inhibition of mTOR activity results in a $\mathrm{G} 1$ phase growth arrest in treated tumour cells resulting from selective disruption of translation of cell cycle regulatory proteins such as D-type cyclins, c-myc and ornithine decarboxylase. When mTOR activity is inhibited, its ability to phosphorylate and thereby control protein translation factors that control cell division is blocked. The antitumour effect of temsirolimus may also in part arise from its ability to depress levels of hypoxia-inducible factors (HIF) and vascular endothelial growth factor (VEGF) in the tumour microenvirionment and thereby impair vessel development (12).

Notwithstanding its novel pharmacological actions, like all anti-neoplastic agents, its adverse reaction may have been of concern. However, in our small sample of patients no adverse events were seen in three patients. None of the patients had significant leucopenia. The majority of the patients had only Grade 1 severity and was easily managed with supportive care. Of interest was the relative frequency of some form of dyslipdemia and interstitial lung disease. These adverse effects are known (13) and others have had similar experience $(14,15))$. The mechanism for hyperlipidemia remains unclear but presumably, being an mTOR inhibitor it is involved in lipid metabolism. The mechanism of development of pneumonitis is also unclear although 
T-cell mediated delayed type hypersensitivity mechanism has been proposed (15). Treatment had to be discontinued in both our patients, one temporarily and the other after 20 doses were given. In the other patient with deranged liver function tests it was only temporarily withdrawn.

The recommendations are that temsirolimus be reserved as the first line only for patients with poor prognosis (6). Based on the results of our albeit small sample, we have shown that temsirolimus has activity even in heavily pretreated patients and it has the added benefits of ease of administration and good tolerability. The results of more randomized controlled trials are needed to confirm whether it has a role even in patients with good prognosis and more importantly to determine optimal sequencing of targeted agents and their role in adjuvant therapy (16).

\section{Acknowledgements}

The author has no potential conflicts of interest to disclose.

\section{References}

1. Lindbald P. Epidemiology of renal cell carcinoma. Scand J Surg 2004; 93: 88-96.

2. Lee CT, Katz J, Fearn PA, P R. Mode of presentation of renal cell carcinoma provides prognostic information. Urol Oncol 2002; 7: 135-140.

3. Patard JJ, Leray E, Rioux-Leclercq N, et al. Prognostic value of histological subtypes in renal cell carcinoma: a multicenter experience. J Clin Oncol 2005; 23: 2763-2771.

4. Eble JN, Sauter G, Epstein JI, IA S. In: Pathology and genetics of tumours of the urinary system and male genital organs. IARC Press. Lyons; 2007.

5. de Reijke TM, Bellmunt J, van Poppel H, Marreaud S, M A. EORTC-GU group expert opinion on metastatic renal cell cancer. Eur J Can 2009; 45: 765-773.
6. National Comprehensive Cancer Network. Practice guidelines in oncology: kidney cancer. 2009.

7. Atkins $M B$, Hidalgo $M$ et al. Randomized Phase II Study of Multiple Dose Levels of CCl-779, A Novel Mammalian Target of Rapamycin Kinase Inhibitor, in Patients with Advanced Refractory Renal Cell Carcinoma. J Clin Oncol 2004; 22: 909-918.

8. Hudes G, Carducci M, Tomczak P, et al. Temsirolimus, interferon alpha, or both for advanced renal- cell acrcinoma. N Engl J Med 2007; 356: 2271-2281.

9. National Cancer Institute. Common terminology criteria for adverse events; 2006.

10. Bjornsti MA, Houghton PJ. The TOR pathway: A target for cancer therapy. Nature Reviews/Cancer 2004; 5: 335-348.

11. Leone $M$, Crowell KJ, Chen J, et al. The FRB domain of mTOR: NMR solution structure and inhibitor design. Biochem 2006; 45: 10294 -10302.

12. Abraham RT. mTOR as a positive regulator of tumour cell responses to hypoxia. Current Topics in Microbiol Immunol 2004; 279: 299-319.

13. Product Information (2008). Temsirolimus concentrate for injection. Wyeth

14. Duran I, Siu LL, AM O, et.al. Characterization of the lung toxicity of the cell cycle inhibitor temsirolimus. Eur J Cancer 2006; 42: 1875-80.

15. Pham PT, Pham PC, Danovitich GM, et al. Sirolimus associated pulmonary toxicity. Transplantation 2004; 77: 1215-20.

16. Motzer RJ, Molina AM. Targeting Renal Cell Carcinoma. J Clin Oncol. 2009; 27: 3274-3276. 